\title{
Las salinas, algunos retos como paisaje cultural \\ Saltworks, some challenges as a cultural landscape
}

Joaquín Sabaté Bel*, Universidad Politécnica de Cataluña

DOI: $10.20868 /$ ciur.2020.129.4403

\section{DESCRIPTORES:}

Patrimonio / paisaje cultural / salinas

\section{KEY WORDS:}

Heritage / cultural landscapes / salt works

\section{RESUMEN:}

Este texto se divide en dos partes. En la primera se muestra como aparece y evoluciona el concepto de patrimonio hasta la aparición de los paisajes culturales. En la segunda se defiende que las salinas constituyen un paisaje cultural singular, se analizan alguna de sus características y riesgos a que están sometidas y se apuntan algunos criterios, para afrontar su puesta en valor.

\section{ABSTRACT:}

This article is divided into two parts. The first shows how the concept of heritage appears and evolves until the emergence of cultural landscapes. In the second one, it is defended that the salt works constitute a unique cultural landscape. We analyse some of their characteristics and risks and point out some criteria to face their value enhancement.

*Joaquín Sabaté Bel es Licenciado en Ciencias Económicas, Doctor Arquitecto y Catedrático de Urbanismo; profesor e investigador en la Universidad Politécnica de Catalunya.

\section{DE LA PROTECCIÓN DE MONUMENTOS A LOS PAISAJES CULTURALES}

La idea de conservar el patrimonio heredado es relativamente moderna. Hasta bien entrado el siglo XIX la construcción de la ciudad europea supone generalmente la paulatina sustitución de los tejidos anteriores. Si bien la Bula del Papa Pío II "Cum alma nostra vitem" (1462), protege los restos de la antigua Roma y supone una clara preocupación por clasificar y conservar elementos antiguos.

Pero sin movernos de Roma, en este caso la de Sixto $V$, basta analizar una de las mejores realizaciones del barroco, para verificar como, aún manifestando una altísima preocupación por la forma urbana, se hace tabla rasa de la ciudad anterior. 
La preocupación por el mantenimiento de los vestigios del pasado nace con la Ilustración. Lo hace con el ensimismamiento de Goethe al descubrir Verona, o con las expediciones y descubrimientos de Heinrich Schliemann de las diversas Troyas. O con la creación en París de la Inspección General de Monumentos Históricos en 1834, siendo su segundo director un ya reconocido Prosper Mérimée, apasionado de la arqueología y los viajes. Mérimée establece unas primeras medidas de protección, en función esencialmente de la antigüedad de las construcciones y de ciertas preferencias estilísticas, cambiantes con el tiempo y con los sucesivos responsables. Encarga a su amigo Viollet-Le-Duc la reforma de la abadía de Vézelay, donde éste afronta por vez primera el problema teórico de la restauración de monumentos. Su principio de que cualquier forma debe ser explicada para ser bella, se traduce en la elaboración de un impresionante Diccionario razonado de la arquitectura francesa, desde el siglo XI hasta el XVI (14 tomos), obra que tiene una notable incidencia.

Esta preocupación por el patrimonio amenazado aumenta con la industrialización. En algunas ciudades aparecen recintos donde se muestran recursos diversos, naturales y culturales (museos de arte, etnográficos y arqueológicos, zoológicos y botánicos). El objetivo es preservar los bienes y generalizar su disfrute público.

Pero esto se consigue a menudo, expoliando rincones lejanos para exhibir en museos sus riquezas, es decir desvinculando el patrimonio del territorio, donde éste se ha creado. Tan solo los paisajes naturales, monumentos de considerable tamaño, y no siempre, o los centros históricos, siguen requiriendo una visita al propio terreno.

Con las crisis industriales y el creciente turismo cultural, aparece una concepción más amplia de patrimonio, como el legado de la experiencia y el esfuerzo de una comunidad. De una concepción estética y restringida a los monumentos, se interpreta ahora de una manera más amplia, como el lugar de la memoria. Deja de mostrarse en recintos y ciudades privilegiadas y se hace en el ámbito donde se ha producido, lo que refuerza su identidad.

Se toma conciencia de su valor como herencia de una sociedad y de su estrecho vínculo con dicha sociedad y su territorio. Surgen con ello nuevas instituciones, instrumentos y conceptos, como los paisajes culturales.

Sus orígenes podemos rastrearlos en diversos escritos de historiadores 0 geógrafos alemanes y franceses de finales del XIX; desde los alegatos deterministas de Friedrich Ratzel, o la atención que Otto Schlütter reclama sobre la idea de landschaft (paisaje) como área definida por una inter-relación armoniosa y uniforme de elementos físicos.

Y también en la incidencia mutua entre naturaleza y humanidad de Vidal de la Blaché. Otros autores como Emile Durkheim y Frédéric Le Play, defienden la relación entre formas culturales y territorio, entre paisaje y paisanaje.

Pero la interpretación actual aparece a principios del siglo XX con el profesor Carl Sauer, que analiza la transformación del paisaje natural en cultural por la acción del ser humano. En "La morfología del Paisaje" (1925) Sauer define paisaje cultural como el resultado de la acción de un grupo social sobre un paisaje natural. La cultura es el agente, lo natural, el medio; el paisaje cultural el resultado. Sauer y los geógrafos de la escuela de Berkeley plantean la idea de 
paisaje como una imagen referida a un territorio, a un lugar concreto, caracterizado por una cultura coherente y estable.

Otra aportación de singular relevancia es la del escritor John Brinckerhoff Jackson, al reclamar atención sobre paisajes y comunidades de la América cotidiana, que ya han defendido Walt Whitman o Mark Twain, haciendo frente a su degradación o desaparición, como también plantean George Perkins Marsh o Lewis Mumford.

Lo que interesa destacar de esta aproximación es que paisaje cultural es un registro humano sobre el territorio; un palimpsesto, un texto que se puede escribir e interpretar, y asimismo reescribir; entendiendo el territorio como artificio.

El extenso legado de Sauer y Brinckerhoff deriva hacia visiones más descriptivas y lo retoma la UNESCO a fines del siglo XX, con una preocupación más administrativa y política, que académica y proyectual. Aunque goza de reconocimiento oficial, todavía hoy constituye un término poco común. Vean sino, las definiciones relativamente complejas de la UNESCO, o las tampoco más claras del National Park Service, la entidad que más paisajes culturales ha promovido.

Por ello sugerimos una definición algo más sencilla: paisaje cultural es un ámbito geográfico asociado a un evento, a una actividad o a un personaje históricos, que contiene valores estéticos y culturales.

O dicho de una manera menos ortodoxa, pero más sencilla y hermosa, paisaje cultural es la huella del trabajo sobre el territorio, algo así como un memorial al trabajador desconocido.

\section{LAS SALINAS, UN PAISAJE CULTURAL SINGULAR}

Atendiendo a esta definición, las salinas constituyen un paisaje cultural muy peculiar por diversas razones. Quizás sea el paisaje cultural que más vida alberga, pues crean un eco-tono entre el ambiente marino y el terrestre. Albergan una amplia riqueza de especies vegetales adaptadas a un medio salado e inundado (algas, lentejas de agua, barrillas y sosas alacraneras). Pero también insectos acuáticos, camarones, anguilas, o artemias. $Y$ atraen otros ilustres visitantes habituales, como garzas, garcetas, correlimos, chorlitejos, fochas, vuelvepiedras y hasta flamencos.

El V Programa Marco de las Naciones Unidas definió el concepto de infraestructuras astutas. Se denominan así aquellas que resultan al mismo tiempo eficientes (funcionales), sostenibles, cultas y bellas. Un ejemplo claro son los canales de Ámsterdam. Han servido eficazmente al transporte de mercancías y personas; se limpian una vez al día aprovechando las mareas; forman parte de una cultura arraigada y son hermosos.

Reivindico también la condición de infraestructuras astutas para las salinas. Son eficientes (nos han alimentado durante siglos), son sostenibles (viento y mareas son su fuente de energía principal), son cultas (están arraigadas en una cultura milenaria) y son bellas; muy bellas, me atrevería a decir. 
Otro aspecto que singulariza a las salinas es su tradición milenaria. La historia de la sal se confunde con la de tantas civilizaciones (sumerios, chinos, babilonios), pero también con culturas de África o de la América precolombina. Todas ellas la adoraron, la necesitaron y comerciaron con ella. Generó impuestos y guerras, pero también topónimos y economías florecientes, o bellas páginas literarias.

Me referiré en particular a las salinas de Canarias, que tuve la oportunidad de conocer en mi juventud. En su conocida sección del valle, Patrick Geddes representa diferentes oficios complementarios. Pues bien, el campesino canario reunía muchos de ellos en una única persona. $Y$ entre otras labores baja en verano a pescar, a mariscar y a recoger sal a la costa, para conservar mejor sus alimentos durante el invierno. Aprovecha la existencia de charcas de pleamar, antecedentes de la riquísima variedad de salinas que se construyen en el archipiélago.

Para ello desarrolla una rica tecnología, que cubre aspectos muy variados: adecuar primero las lajas costeras, y construir después una rica urdimbre de pocetas. Aún siendo unas pequeñas islas en medio del Atlántico, desarrolla una rica tipología de salinas, algunas naturales, aprovechando charcos de pleamar sobre barro aluvial o cantiles costeros rocosos.

La mayor parte de estas salinas son artificiales, y podemos distinguir cuatro familias. La primitiva sobre roca imita las maretas, aprovechando cocederos naturales. Se trata de buscar el cuajo, como dicen los cabreros, o sea localizar el terreno más apropiado para que cuaje la sal. La segunda, de obra mural con mortero de cal, tiene una larga tradición, desde la época romana hasta el siglo XIX. En Canarias las más antiguas son las de la isla del Hierro. Las tercera familia, salinas antiguas de barro, es la que tiene más representantes. Suelen construirse bajo el nivel de pleamar, y tener un cristalizador dividido en diversos tajos. Finalmente, las salinas nuevas de barro con fondo de piedra son una sabia adaptación en una tierra, como Lanzarote, carente de recursos, y donde la imaginación colectiva ha diseñado artilugios tan ingeniosos, como los cortavientos de los sembrados, los arenales, las maretas o las gerias.

Pero la tecnología no se queda solo en la forma y materiales de los cocederos, caños, vasos, tajos y taludes. También se aplica a los ingeniosos sistemas de captación del agua del mar. Existe una rica diversidad de tomaderos, bufaderos o estancaderos (en callao, en rasa, inclinado, en caño, en cantil, excavados o con pozo y molino), que se diferencian en función de si el agua entra, salta o corre.

Destaca asimismo la creciente sofisticación de los molinos salineros, amontonaderos, escurrideros, cocederos y saleros; y una extensísima variedad de herramientas, ya sea para buscar materias primas, o para la construcción o mantenimiento, diversas según el tipo de salina.

La actividad en las salinas genera no tan solo paisajes de singular valor y belleza. También da lugar a un patrimonio inmaterial de singular valor. En otros artículos se habla de comida, de poesía, de música, de vida en definitiva. Me gustaría reivindicar aquí "Las Seguidillas del Salinero" de Los Sabandeños, uno de los grupos folklóricos más importantes de la historia. Un modesto y casi anónimo poeta popular, Víctor Fernández, apodado "El Salinero" por trabajar en Janubio (Lanzarote), las transcribe desde su memoria al papel con 70 años. Los 
Sabandeños les ponen música, homenajeando el origen manchego de este género, pero a su vez el valor añadido de su paso por diferentes islas.

Quiero destacar otros dos aspectos: los recuerdos y las personas, el lenguaje y los salineros, porque ambos me han enseñado ricas lecciones.

Un territorio con muchos topónimos es un territorio muy vivido, muy apreciado. Porque solemos dar nombre tan solo a aquello que apreciamos, que tiene significado para nosotros. El desempeño de una actividad que como el arte de extraer la sal genera numerosos topónimos, que son fiel reflejo de su riqueza. El listado de términos utilizados en las salinas canarias, relativos a su arquitectura, herramientas, norias y operarios, es larguísimo. Y lo más interesante es que son términos diferentes a los utilizados en Baleares o Andalucía.

Otra lección que aprendimos trabajando los últimos treinta años en diversos paisajes culturales, es la importancia de los recuerdos. Constituyen recursos culturales fundamentales. Los vestigios de otros tiempos, la memoria colectiva, el patrimonio compartido y las tradiciones culturales de una determinada comunidad son tan importantes, o incluso más, que sus monumentos. Conviene pues prestar especial atención a las memorias asociadas a un recurso, evitar que se pierdan, recopilar historias, documentar, interpretar, antes de que desaparezcan esos vestigios.

La interpretación exige explicar aquello que permita a una persona hacerse una idea precisa de las condiciones de vida de un momento dado (tipo de producción, cultura, hábitos de alimentación y vestido...). La investigación de un periodo, de una sociedad, de la transformación de un modo de vida, de unos recursos... constituye un ingrediente fundamental de las iniciativas de los parques patrimoniales de mayor interés.

Otra lección aprendida es que los residentes constituyen los principales recursos. Son realmente esenciales en su futuro, tanto por sus conocimientos, recuerdos e historia, como por su entusiasmo, una vez que reconocen el valor del patrimonio acumulado. En definitiva porque ellos son la verdadera razón para impulsar una iniciativa, los principales agentes interesados en valorizar su patrimonio, en mantenerlo y adecuarlo. Tan pronto se refuerza su autoestima, dejan de sentirse parte de un territorio en crisis, para empezar a construir un futuro sobre aquellos recursos patrimoniales. Las mejores iniciativas así lo reconocen, e incorporan a los residentes en su diseño y promoción. Los mejores proyectos analizados son ampliamente participativos.

Lo más importante es por tanto, reforzar la autoestima de los residentes. Los visitantes, museos e inversiones ya vendrán después.

\section{LA FRAGILIDAD DE UN RECURSO}

Las salinas son extremadamente frágiles. Lo son por factores externos y propios. Entre los primeros, cabe destacar que el frigorífico reduce drásticamente la tradición de salar los alimentos para mantenerlos; disminuyendo la demanda de este elemento. Pero encima surge esta dichosa creencia, un verdadero oxímoron, de que la sal es perjudicial para la salud. 
Otros factores que explican su fragilidad son específicos de las salinas. La mayor parte se construyen al borde del mar, en terrenos llanos, con un cierto nivel de insolación, tejiendo sobre ellos una hermosa urdimbre de canales y piscinas de escasa profundidad. En definitiva, preparándolos para que la codicia y la escasa conciencia de su valor como testimonio de una cultura secular, los predispongan a ser ocupados por complejos hoteleros, o por grupos banales de apartamentos.

En alguna ocasión esto da lugar a obras interesantes, como el hotel Las Salinas, de Fernando Higueras y César Manrique, pero generalmente no es así. Y recordemos como el propio Fernando declara poco después, que lo mejor que ha hecho en Lanzarote es no ejecutar varias de sus obras.

Son innumerables las salinas que han desaparecido en Canarias, y es urgente frenar esta pandemia. Recuerdo con tristeza como vi desaparecer alguna, que incluso habíamos protegido como Bien de Interés Cultural. De la cincuentena larga que aún quedaban en los años noventa, hoy ya no existen más de la mitad. Un $40 \%$ mantiene algo del trazado, y quedan en pleno funcionamiento apenas un $7 \%$, o por decirlo más descarnadamente, tan solo cuatro.

Y lo que la codicia o la ignorancia no ha conseguido arrasar, puede estar amenazado ahora por el cambio climático, por la subida del nivel del mar.

Estos hermosos testimonios construidos de una cultura milenaria requieren de muchos esfuerzos, de la alineación astral de estudiosos, agentes locales y administraciones sensibles.

¿Qué podemos hacer más allá de un homenaje gráfico, o una rememoración arqueológica?

\section{A MODO DE CONCLUSIÓN}

Acabo con tres consideraciones con respecto a este patrimonio singular.

La primera es que, como paisaje cultural frágil, como territorio cargado de recursos, y por ello mismo, muy delicado, es absolutamente imprescindible la existencia de un proyecto. Un proyecto en su acepción más amplia y ambiciosa, una visión, un modelo ilusionante y compartido hacia el que avanzar. No son suficientes los planes urbanísticos, ni siquiera todas las medidas preservadoras de los planes de protección. No se trata de sumar intervenciones más o menos afortunadas, sino de plantear un conjunto de objetivos consensuados con la población y los agentes del territorio, donde todos se sientan partícipes.

Existe una amplia experiencia de planes de impulso regional basados en el patrimonio, que muestran la trascendencia de esta exploración, así como los retos de una experiencia novedosa.

Todos contemplan idénticas premisas: identificar recursos de interés y ofrecer una interpretación estructurada y atractiva de los mismos, y narrar una historia, capaz de atraer visitas e inversiones, de descubrir oportunidades de actividad y áreas de proyecto, de situar el territorio en condiciones de iniciar un nuevo desarrollo. Así lo intentamos, por ejemplo, en Tierra del Fuego (Chile), 
redescubriendo los vestigios de diferentes culturas, que el viento quería borrar y la nieve pretendía cubrir.

Muchos proyectos que hemos analizado, o donde hemos intervenido, tienden a cubrir unos mismos estadios. En primer lugar conviene evitar el futuro deterioro de los recursos. Muchos de dichos recursos son de tamaño considerable, costosos de mantener y de reutilizar. Pero mantenerlos es crucial, como parte sustancial de nuestra historia, de nuestro patrimonio cultural.

Una primera medida debe ser protegerlos, si es preciso vinculándolos a algún tipo de preservación legal, deteniendo su posible deterioro.

Pero esto no es suficiente. Hay que ir mucho más allá; pensar que hacer con esos recursos, como reutilizarlos imaginativamente. $Y$ tampoco esto resulta suficiente; hay que interpretarlos y ponerlos al servicio de una estructura más general, del guión de una historia.

Para conseguir estos objetivos es imprescindible atraer la conciencia pública. Los recursos patrimoniales no están habitualmente "instalados" en la conciencia colectiva. De ahí la necesidad imperiosa de la divulgación de sus valores. Solo si se atrae dicha atención, aparecerán políticas, inversiones para su preservación.

La segunda conclusión es que la rica complejidad de los paisajes culturales exige un nuevo marco conceptual y nuevos métodos e instrumentos, un cierto esfuerzo creativo, porque no podemos abordarlos desde el edificio teórico, el marco administrativo, o los instrumentos del planeamiento tradicional. Una lección interesante que estamos aprendiendo, es la necesidad de integrar estructuras físicas y narrativas, tangibles e intangibles. Del análisis de los proyectos más significativos podemos destacar que la gestión inteligente del patrimonio supone un factor clave, porque atrae turismo e inversiones, genera actividades y puestos de trabajo y muy fundamentalmente, porque refuerza la autoestima de la comunidad.

En tercer lugar, la herencia cultural no se debe simplemente preservar. Puede generar oportunidades de desarrollo donde coexistan valores históricos y nuevos valores territoriales. Hay que superar una posición meramente conservacionista del patrimonio. La construcción de hoy puede también generar identidades y patrimonio mañana. "La preservación a través de la transformación", bien podría ser el enunciado sintético.

Creo que los paisajes culturales y entre ellos las salinas, están llamados a jugar un papel relevante, porque constituyen la expresión de la memoria, de la identidad de un territorio, identidad asimismo como proyecto que se puede ir enriqueciendo sucesivamente.

No es tan solo cuestión del mero mantenimiento de un legado patrimonial. Hoy más que nunca frente a la globalización, tematización y banalización de tantos paisajes, debemos apostar por intervenir en ellos valorando su identidad y su memoria.

Una lección bien interesante que hemos aprendido en estos proyectos es que en el código genético de cada paisaje esta su alternativa. Y que para intervenir en él debemos conocerlo y respetarlo, integrando estructuras físicas y narrativas, tangibles e intangibles, para ponerlo en valor a través de su transformación. 
Aprendamos pues a conocer y respetar nuestras salinas.

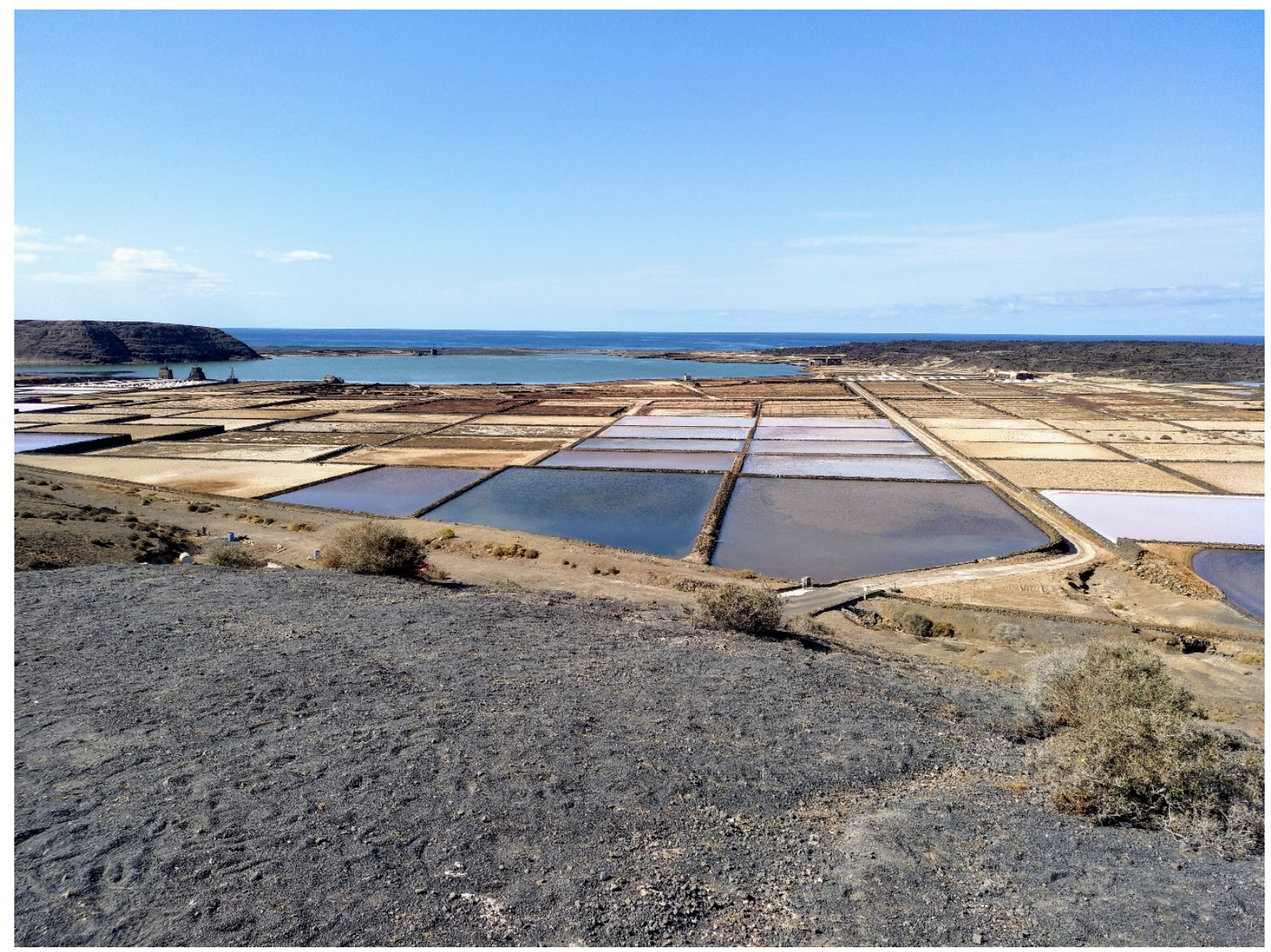

Figura 11. Salinas de Janubio

Fuente: Joaquín Sabaté Bel

\section{BIBLIOGRAFÍA}

AA.VV. Avance Plan Insular de Ordenación del Territorio. Cabildo Insular de Tenerife, 1994.

AA.VV. Proyectando el eje del Llobregat. Paisajes culturales y desarrollo regional. Designing the Llobregat Corridor. Cultural Landscape and Regional Development. Universidad Politécnica de Cataluña y Massachusetts Institute of Technology. Barcelona, 2001.

AA.VV. Everyday America. Cultural landscape studies after J.B. Jackson. University of California Press. Berkeley, 2003.

Luengo, A. Y Marín, C. El jardín de la Sal. Ecotopia Ediciones Tenydea. Santa Cruz de Tenerife, 1994.

Sabaté, J. "Algunas pautas metodológicas en los proyectos en paisajes culturales" en La práctica del urbanismo, editado por Luís Moya. Editorial 
Síntesis. Madrid, 2011.

Sauer, C. "Morphology of landscape". University of California Publications in Geography, 2 ( $n^{\circ} 2$ ). Berkeley, 1925.

Soria y Mata, A. "El territorio como artificio", en Obra Pública no 11, primavera 1989. 